\section{MODELOS PARA LA INVESTIGACIÓN CON EMBRIONES}

\author{
M. a Teresa López de la Vieja \\ Universidad de Salamanca, Facultad de Filosofía \\ tlv@usal.es
}

\section{SOME MODELS FOR EMBRYO RESEARCH}

Cómo citar este artículo/Citation: López de la Vieja, M. T. (2013). "Modelos para la investigación con embriones". Arbor, 189 (763): a066. doi: http://dx.doi.org/10.3989/ arbor.2013.763n5003

Recibido: 13 julio 2012. Aceptado: 6 junio 2013.

RESUMEN: Los modelos son relevantes para la teoría y para la práctica de la investigación con embriones. La Ley del año 2007, de investigación biomédica, ejemplifica la posibilidad de regular este tipo de investigación y, al mismo tiempo, establecer condiciones para autorizar proyectos y prácticas. Por un lado, el modelo gradualista considera que el desarrollo tiene diferentes etapas $y$, por lo mismo, ha de tener distintos grados de protección. Por otro, el modelo no gradualista rechaza este tipo de investigación, al defender la protección de la vida humana, desde sus inicios. Los desacuerdos en torno al tema demuestran que se trata de una cuestión que sigue siendo polémica, en la Unión Europea y en otros países. El artículo defiende que, en sociedades pluralistas, el respeto por todos los enfoques y modelos llevará a regular la investigación biomédica, no a prohibir prácticas acordes con una determinada noción de la vida humana.

PALABRAS CLAVE: Ética; Bioética; Investigación con embriones; Pluralismo; Gradualismo.
Copyright: (C) 2013 CSIC. Este es un artículo de acceso abierto distribuido bajo los términos de la licencia Creative Commons Attribution-Non Commercial (by-nc) Spain 3.0.

ABSTRACT: Different models to approach research on embryos are relevant in theory and in practice. The Spanish Act of 2007 could exemplify the possibility of regulating research on human pre-embryos and, at the same time, establishing clear requirements to accept projects and practices. On the one hand, the gradualist model usually considers different levels of development and, for this reason, different levels of protection of human life. On the other hand, the nongradualist model rejects research on embryos, since it defends the protection of human life from the very beginning and in general. Disagreements about the topic and different laws only prove that it is still a difficult issue in European and other countries. The article argues that, in plural societies, respect for all perspectives and models requires to regulate biomedical research rather than prohibiting certain practices that are coherent with a specific idea of human life.

KEYWORDS: Ethics; Bioethics; Research on embryos; Pluralism; Gradualism. 


\section{INTRODUCCIÓN}

En el capítulo primero de este título se prohíbe expresamente la constitución de preembriones y embriones humanos con fines de experimentación y se autoriza la utilización de cualquier técnica de obtención de células troncales humanas con fines terapéuticos o de investigación. (Ley 14/2007, de 3 de julio, de Investigación biomédica, Preámbulo IV).

En el año 2007 entró en vigor la Ley de Investigación Biomédica, para regular temas tan controvertidos como el uso de las técnicas genéticas, el acceso a datos genéticos de carácter personal y la utilización de células troncales para la investigación. Se permitirá cuando esta tenga una finalidad terapéutica; en general, la norma establece condiciones y garantías para acceder a innovaciones técnicas que han sido objeto de numerosas controversias a lo largo de los últimos años. En cierto modo, la legislación ha cruzado una frontera que parecía insalvable poco tiempo antes, ya que los temas de los cuales se ocupan han generado tensiones en la opinión pública, en casi todos los países. Cabe pensar que la legislación anterior sobre aspectos biomédicos -en especial, la Ley 14/2006 que regula técnicas de reproducción asistida, desde la inseminación artificial, la fecundación in vitro hasta la transferencia de gametos- fue la ocasión para comprobar que pueden haber garantías suficientes para ampliar las posibilidades técnicas y, a la vez, respetar la autonomía de los individuos. La investigación con embriones in vitro es, tal vez, uno de los temas más sensibles y, por lo mismo, requiere marcos normativos claros. Esto es, por un lado existen importantes diferencias sobre los avances en investigación biomédica - diferencias e incluso tensiones morales, políticas o ideológicas-, por otro lado estos avances han de ser compatibles con el respeto por las libertades y los derechos fundamentales. Aun así, el peso que tengan las diferencias y el grado de protección de tales derechos dependerán de la forma de entender el comienzo de la vida.

En este artículo se argumenta que la probabilidad de llegar a acuerdos básicos en torno a la investigación biomédica, y sus límites, dependerá en gran medida del enfoque general, teórico, sobre el desarrollo de la vida humana, gradualista o no gradualista. (1) La legislación nacional parece haber adoptado el modelo gradualista y, por ello, contempla la protección de la vida, solo que se trata de un tipo de protección acorde con el nivel de maduración. Las posiciones contrarias a la aplicación de ciertas técnicas biomédicas responden a un modelo completamente distinto, no gradualista y de protección absoluta; este modelo ha sido adoptado en algunos países, los menos, con consecuencias importantes. En el tema de la investigación con embriones in vitro confluyen, pues, ambos enfoques y con resultados prácticos bien distintos. En tal sentido, el carácter diagnóstico o farmacéutico de la investigación sería secundario, lo fundamental es el modo de entender y de valorar el desarrollo embrionario. (2) Los informes, las recomendaciones de expertos y comités, así como la legislación de varios países registran las tensiones entre ambos modelos teóricos. Teniendo en cuenta el contexto de los debates, el pluralismo que caracteriza a la cultura moral y política contemporánea, no cabe pensar en una protección absoluta de la vida ni en prohibir determinadas técnicas, de lo contrario ¿cómo tomar en serio diferencias y enfoques opuestos? Es decir, seguirán existiendo discrepancias ideológicas y creencias que puedan llevar a valoraciones encontradas sobre el uso de los conocimientos biomédicos, sobre los límites de la técnica al comienzo o al final de la vida, así como sobre las fronteras de la existencia y la dignidad individual o sobre el significado de la salud y de la muerte. (3) Con todo, las normas que a todos obligan deberían ser equidistantes o, al menos imparciales, aun sin ser neutrales en origen. La legislación nacional sobre estos temas confirma que el modelo gradualista no obliga -el modelo no gradualista sigue siendo posiblesi bien crea un espacio definido para la investigación con embriones. No ocurriría lo mismo si solo se atendiera al modelo no gradualista, ya que este excluiría varias técnicas o usos de estas técnicas, en aras de la protección absoluta de la vida.

La conclusión sería, entonces, que las discrepancias entre gradualistas y no gradualistas no han de impedir que se regulen las condiciones generales para la investigación con embriones, contribuyendo a la transparencia y a la seguridad. No cabe duda de que el tema sigue suscitando tensiones ideológicas, entre la demanda de protección completa y, por otro lado, las garantías proporcionales al nivel de desarrollo. Ahora bien, tal vez estas tensiones pudieran dar paso a otros debates sobre riesgos y beneficios, sobre motivos reales y motivos aparentes de inquietud, sobre posibles abusos y las garantías necesarias para impedir cualquier probable exceso en el ámbito de la investigación. Un pluralismo consecuente no puede ignorar creencias e ideologías en liza, pero tampoco eliminará las condiciones que hacen posible la coexistencia de diferentes formas de entender la vida, la salud, la muerte y el uso de los conocimientos. 


\section{MODELOS}

«Preembrión»: el embrión constituido in vitro formado por el grupo de células resultante de la división progresiva del ovocito desde que es fecundado hasta 14 días más tarde. (Ley 14/2007, de 3 de julio, de Investigación biomédica art.3, s).

Desde el año 2006, la legislación española regula el uso de preembriones conservados y, por tanto, no empleados tras la aplicación de técnicas de reproducción asistida. Al margen del interés por distinguir entre embriones y preembriones - hasta catorce días después de la fecundación ${ }^{1}$ - la normativa especifica las condiciones para el uso y, en su caso, para la donación de estos o de tejidos crioconservados. La cesión a otros del preembrión con finalidad reproductiva y la cesión a equipos que investigan han de contar siempre con el consentimiento informado de la donante o de la pareja, si la hubiera. Es más, este procedimiento ha de ser renovado cada dos años, de forma que ningún centro podrá disponer de los preembriones, a menos que demuestren la imposibilidad de obtener la correspondiente autorización de los interesados, incluso cuando haya pasado el plazo establecido para renovar el consentimiento ${ }^{2}$. Se entiende que este será siempre por escrito, libre e informado ${ }^{3}$. Los requisitos marcados por la ley se refieren también a otros aspectos, como son la mayoría de edad de las donantes, el carácter altruista, no lucrativo de la donación, la confidencialidad del procedimiento y la posibilidad de revocar la decisión tomada por los donantes ${ }^{4}$. Los centros en los cuales se realicen las técnicas de reproducción asistida, así como los centros responsables de la conservación de gametos, también aquello en los que tenga lugar la investigación, todos han de contar con la autorización de los organismos competentes. Lo mismo cabe decir de los equipos biomédicos y de los proyectos ${ }^{5}$, ya que han de cumplir determinadas condiciones y han de estar supervisados por la Comisión Nacional de Reproducción Asistida.

La autorización es también preceptiva para aquellos centros que practiquen técnicas para la detección de enfermedades hereditarias, como es el diagnóstico preimplantacional, ya que este implica la selección embrionaria 6 . La legislación establece, por tanto, varias condiciones y requisitos, a fin de asegurar el respeto por las decisiones de los pacientes y de los afectados, en una línea claramente garantista. Desde $1988^{7}$, fecha en que entró en vigor la primera ley sobre el tema, el objetivo básico ha sido impedir el uso encontrado, el tráfico o transporte no autorizado de gametos y óvulos fecundados. Desde entonces, en
España está prohibida la fecundación de óvulos con fines distintos a la procreación ${ }^{8}$. Tampoco se permite la donación de gametos y preembriones con fines comerciales ${ }^{9}$; sin embargo, la existencia de un marco normativo claro para la investigación que pueda afectar a la integridad de los embriones humanos no parece suficiente para quienes defienden el valor absoluto de la vida humana. En consecuencia, estos rechazan cualquier procedimiento, cualquier práctica que la ponga en riesgo. A ese respecto, no es significativo que se trate de preembriones, de embriones o de no nacidos, tampoco que haya propósito diagnóstico o terapéutico en la investigación.

Resulta evidente que el debate sobre el uso de embriones $^{10}$ se ha agudizado desde finales de los años noventa, a raíz de los avances en genética, si bien la raíz de las diferencias sobre el principio y el final de la vida está en el modo de entender el desarrollo humano. La normativa vigente en España ha seguido el criterio de protección no absoluta de la vida humana, un criterio que han aplicado también varios países del entorno europeo; por tanto, la legislación nacional sobre reproducción asistida y sobre investigación va en la misma dirección que varias recomendaciones e informes elaborados en la Unión Europea. Existe también continuidad entre la legislación reciente - de 2006 y de 2007- y las normas anteriores sobre esta materia, normas nacionales e internacionales. Aún así, las últimas leyes han sido cuestionadas por quienes entienden que la vida tiene el mismo valor (Glover, 1999) y merece el mismo respeto en todas las etapas, desde el momento de la fecundación. En cambio, los enfoques gradualistas insisten en las diferencias entre el ser humano en estado potencial y el seres humanos, por tanto, la experimentación con preembriones (Singer, 1999) es una práctica aceptable, correcta. Las tensiones han sido y son, pues, evidentes. Ahora bien, con independencia de las diferencias ideológicas en torno a esta cuestión, el debate sobre estas cuestiones prueba que el modelo gradualista y el no gradualista se basan en premisas opuestas.

- El modelo gradualista ha sido tenido en cuenta en varios documentos, elaborados y suscritos en la Unión Europea, que tratan en forma diferenciada la protección de la vida humana en el ámbito biomédico. Los matices se aprecian, sobre todo, en el Informe CDBI de 2003 (Steering Commitee on Bioethics, 2003) que se ocupaba de la protección de embriones, reconociendo la existencia de posiciones morales diferentes y la distancia entre seres humanos potenciales y personas. En con- 
secuencia, adoptaba el modelo gradualista. En el Informe SEC sobre células troncales (Commission of the European Communities, 2003) estaba también la distinción entre preembriones y embriones, considerando su donación para los proyectos de investigación. La dificultad para llegar a consenso en la materia era reconocida por la Opinión del GEE - Grupo Europeo de Ética- del año 1998 (Commission Européenne, 1998) sobre aquellos proyectos en la Unión Europea que empleen embriones; por un lado admitía la pluralidad cultural, la diversidad de concepciones morales, por otro recomendaba transparencia en la investigación, aceptando la definición estándar de "preembriones" y las legislaciones nacionales que permitan investigar con ellos. El tema de los derechos y la protección eran los objetivos del Convenio de Oviedo, de 1997, para el ámbito de la medicina y de la biología. La traducción normativa del modelo general no ha sido igual en los países europeos; en Francia, la ley $2004-800^{11}$ prohíbe la investigación con embriones, si bien admite algunas excepciones, como el consentimiento de la pareja - la finalidad terapéutica. En cambio, el Informe de 2005 sobre ciencia y tecnología de la House of Commons (2005) distinguía claramente la vida humana con plenos derechos de los estadios anteriores, que requieren otro tipo de protección. El documento recomendaba que el Reino Unido adoptase una legislación flexible sobre estos temas, pero seguía considerando que la clonación es aun una técnica poco segura y que, además, plantea cuestiones de tipo ético. No eludía temas controvertidos, como la creación de embriones con fines de investigación (House of Commons, 2005) o la clonación reproductiva, pero mantenía serios reparos con respecto al uso de esa técnica, por sus posibles aplicaciones. Este informe mantiene el enfoque adoptado años atrás por la Human Fertilisation and Embryology Act (British Parliament, 1990) que, a su vez, seguía de cerca la posición defendida con anterioridad en el Informe Warnock, de 1984 (Committee on Human Fertilisation and Embryology, 1984). En este, quedaba muy claro el enfoque general, de tipo gradualista, para los temas relativos a la investigación biomédica. Más allá del espacio europeo, otros países han aceptado también este modelo, asumiendo la tesis de etapas de desarrollo en la vida humana, como demuestran los argumentos empleados por el Advisory Panel on Research del año 2005, en Canadá, para aceptar la investiga- ción con embriones, y rechazar su creación con estos fines o para obtener híbridos (Government of Canada, 2005). El hecho de que la legislación francesa admita excepciones, que los informes británicos hagan recomendaciones para cada una de las técnicas, que la opinión de los expertos canadienses se refiera a los preembriones y a los embriones, todo ello indica que la protección no absoluta es compatible con la investigación con embriones, siempre que esté regulada y cuente con las garantías apropiadas. En cualquier caso, la tesis general es que el preembrión y el embrión no tienen el mismo estatus que el nacido (Tauer, 1997); la protección habrá de ser también distinta (Klinkhammer, 2000).

- El modelo opuesto, no gradualista, es la base de normas y documentos restrictivos en esta materia, cuyo objetivo es garantizar la protección absoluta. En Alemania, la ley de 1990 - Gesetz zum Schutz vom Embryonen (EschG) - pretendía asegurar este aspecto, siendo aún más precisa la normativa del año 2002 sobre investigación con células troncales ${ }^{12}$, siendo esta aceptable solo bajo ciertas condiciones y con la correspondiente autorización. En el 2001, la opinión expresada por la Deutsche Forschungsgemeinschaft era aún minoritaria, ya que la opinión más común se parecía bastante a las tesis defendidas por el entonces presidente J. Rau. El cuestionaba en modo abierto este tipo de investigación y, en general, el uso de las nuevas técnicas al comienzo de la vida; lo hacía en nombre de un progreso científico a medida de los seres humanos. Con todo, la tesis de que la dignidad de la vida humana no está amenazada por el uso de las técnicas biomédicas ha tenido también defensores en Alemania, como sucede con el jurista y escritor B. Schlink (Schlink, 2002). Otros autores han interpretado que los desacuerdos éticos en este campo son apenas una muestra del pluralismo alcanzado por la sociedad alemana (Kieckbush, 2002). En esos mismos años y en Estados Unidos, el President's Council daba a conocer sus conclusiones sobre la reproducción asistida, en una línea similar. El informe de 2004, Reproduction and Responsibility: The Regulation of the New Biotechnologies ${ }^{13}$, se ocupaba de la investigación con embriones, de las células troncales y de otros temas polémicos en este campo. Autores como J. Childress han llamado la atención sobre las discrepancias osar técnicas que implican destrucciones de embriones (Childress, 1999). En una línea similar, P. Lau- 
ritzen ha cuestionado la orientación individualista de la investigación que sigue un marcado enfoque liberal, así como el predominio del lenguaje de los derechos en este debate (Lauritzen, 2003). En cambio, M. Sandel no apreciaba dificultades morales especiales en este tema, la investigación con embriones (Sandel, 2005). Desde el año 2001, el entonces presidente G.W. Bush ha expresado sus opiniones sobre los embriones in vitro y sobre el uso de las células troncales, así como sobre el valor propio de la vida humana, en todas sus fases (President's Council on Bioethics, 2001). El argumento de la dignidad intrínseca y del respeto debido a la vida humana potencial ha sido el eje fundamental de las criticas más conocidas de la Iglesia católica hacia los avances biotecnológicos. Desde 1985, este punto de vista ha quedado bien reflejado en la doctrina del Evangelium vitae y su afirmación del valor de la persona humana (Ioannes Paulus, 1995, 03, 25, 12, 58, 63, 29). A partir de 1987, la Congregazione per la Dottrina della Fede ha llevado está posición doctrinal al debate sobre el uso de células troncales y sobre la investigación con embriones. Es significativa a este respecto la intervención de arzobispo J.L Tauran en la Pontificia Accademia per la Vita, en el año 2000, ya que sintetizaba bien la posición del Vaticano sobre la experimentación con embriones y el pleno respeto al patrimonio genético (Pontificia Accademia per la vita, 2000). En los años posteriores se han afianzado algunas de estas tesis sobre la investigación biomédica (Pontificia Accademia per la vita, 2003) y sobre el bien de la vida humana, entendida como unidad personal ${ }^{14}$. Es claro que estos principios no son compatibles con el uso de embriones o de preembriones, sea cual sea su finalidad científica. Las consecuencias de esta doctrina de la Iglesia han sido extraídas en algunos países como Costa Rica. Desde el año 2000, a resultas de la sentencia de Corte Suprema de Justicia, -Sala Constitucional en San José (Tribunal Constitucional de Costa Rica, 2000) - está prohibida en ese país la fertilización in vitro, por respeto a la vida y a la dignidad humanas.

En este caso y en otros análogos, se entiende que el valor propio de los seres humanos y el respeto riguroso por los derechos fundamentales obligan a fijar límites claros para la investigación que implique a los humanos, sea cual sea el potencial terapéutico de técnicas y de conocimientos. Los seres humanos no han de ser manipulados ni tratados como productos ni conviene hacer uso de técnicas de consecuencias imprevisibles, abriendo así la caja de Pandora (Tighe, 1999), por así decirlo. En este modelo, la protección de la vida ha de ser completa ${ }^{15}$ - para nacidos y no nacidos-, sin excepciones. Para el modelo gradualista son asimismo fundamentales el respeto por los derechos y el reconocimiento de la dignidad, sin embargo, no se reconoce un momento especial para lo humano (Warnock, 2002). Según esto, el tratamiento de la vida potencial ha de ser distinto al que corresponde a la vida real. Se entiende que no procede una consideración idéntica de etapas diferenciadas, ni la protección de los preembriones será como la de los embriones, los fetos, los nacidos. Por tal razón, admite niveles de protección no absoluta, una tesis que empiezan a asumir países antes reticentes a la investigación con embriones y, en conjunto, al modelo gradualista, como Alemania (Zentralen Ethikkommission, 2001; 2006). Están, además, las cuestiones ideológicas como trasfondo del debate, estando en el origen de las divergencias sobre el comienzo de la vida; los documentos e informes sobre el tema indican, sin embargo, que el desencuentro comienza con el modelo sobre el que se asientan leyes, interpretaciones y tradiciones.

\section{TENSIONES}

"Los embriones humanos que hayan perdido su capacidad de desarrollo biológico, así como los embriones o fetos humanos muertos, podrán ser donados con fines de investigación biomédica $u$ otros fines diagnósticos, terapéuticos, farmacológicos, clínicos o quirúrgicos." (Ley 14/2007, de 3 de julio, de Investigación biomédica, art. 28.1).

La Ley 14/2007 permite investigar con embriones, con finalidad terapéutica y siempre que se cumplan determinadas condiciones. A este propósito la norma, remite a las sentencias del Tribunal Constitucional que avalaban el enfoque gradualista en este ámbito. Consecuente con ello, la norma rechaza la creación de embriones con destino a la investigación, al tiempo que acepta el uso de células troncales cuando los proyectos satisfagan determinadas condiciones y estén debidamente autorizados. Siguiendo este criterio, la ley regula más temas polémicos, como el cribado genético y otras técnicas que implican selección de embriones ${ }^{16}$, zanjando así algunos de los debates sobre la nueva eugenesia y sobre los abusos que se pueden cometer con la manipulación genética. Una norma anterior, la Ley 14/2006 (artículo 12), autorizaba el diagnóstico preimplantacional y la selección embrionaria, con el propósito de evitar enfermedades hereditarias y, a su vez, la norma modificaba la legislación precedente -el Real Decreto 2132 del año $2004^{17} \mathrm{y}$ 
la Ley 42/ $1998^{18}$-, sobre investigación y sobre reproducción asistida, lo cual indica que el interés por los derechos de los posibles afectados ha prevalecido sobre el rechazo a las técnicas de reproducción y a los ensayos con embriones in vitro. En todos los casos, la finalidad ha sido la protección de la dignidad y de la integridad de los sujetos de la investigación biomédica, en la línea marcada desde hace algunos años por los informes nacionales ${ }^{19}$ e internacionales y por las recomendaciones de la Unión Europea, si bien se ha hecho en términos distintos a los de la legislación adoptada en otros países europeos. Lo cual demuestra que los acuerdos son posibles en el modelo gradualista, siempre que se respeten espacios para la diferencia con otras versiones sobre la vida y su desarrollo.

1. La Ley $14 / 2007$ regula aspectos básicos, como es la donación de los embriones, la de ovocitos, el modo de obtención de las células embrionarias y los requisitos para realizar cualquier investigación en este campo. Lo mismo cabe decir sobre las normas anteriores, como la Ley 14/2006, que también establecía varias condiciones para donar y utilizar preembriones, procedentes de las técnicas de reproducción asistida y crioconservados en centros autorizados para ello, y de la primera ley del año 1988. Ninguno de los procedimientos será posible sin el previo acuerdo de los interesados, la donante y, si fuera el caso, también el de su pareja, asegurándose, además, la confidencialidad de la información sobre todo el proceso y el carácter no lucrativo, altruista, de la cesión de los preembriones a otra pareja o a los centros de investigación. El consentimiento libre e informado habrá de ser renovado cada dos años ${ }^{20}$, lo cual indica que la autonomía de los donantes debe prevalecer sobre otro posible interés. Estas y otras restricciones están destinadas a evitar cualquier tipo de transacción comercial y, en especial, las posibles irregularidades en la donación de tipo internacional ${ }^{21}$. En tal caso, quienes procedan de otros países estarán sujetos a las condiciones establecidas por la ley española. Esto mismo vale para los centros e instituciones extranjeras, evitando así abusos con donantes, como los que fueron descubiertos en centros de Rumania e Inglaterra.

2. La clonación reproductiva está prohibida en la legislación nacional. En cambio, la nueva ley sí permite la clonación con fines terapéuticos ${ }^{22}$. Con respecto a lo primero, la normativa española sigue el criterio general de la Unión Europea des- de 1998 y, sobre todo, desde la Carta de Niza del año 2000. Tal vez haya que esperar años antes de contar con un espacio integrado para la investigación y para la reflexión bioética en los países europeos, pero algunos temas biomédicos, como este, indican que se han dado pasos para construir acuerdos sobre la materia. Las diferencias siguen existiendo, la posibilidad de acuerdos también. Se puede observar, en cambio, opiniones más abiertas sobre este tema en otras tradiciones, judías y musulmanas (Barilan, 2006; Eich, 2006). La legislación española está, por lo tanto, dentro de este marco que se va construyendo en distintos países, para clarificar los procedimientos y para garantizar las libertades de los ciudadanos. Por ejemplo, las leyes nacionales y la ley francesa del año $2004^{23}$ mantienen idéntico criterio sobre la clonación, también en cuanto a la necesidad de prohibir las prácticas eugenésicas. Ahora bien, no existe tal acuerdo en lo que se refiere a la investigación con embriones, ya que la legislación francesa no la admite, a pesar de que acepte algunas excepciones cuando exista el consentimiento de la pareja. Esto sucede de nuevo con la procreación asistida, que tiene un tratamiento distinto en las leyes españolas, desde 1998 hasta 2006, y las aprobadas en Francia. El análisis comparativo indica que, en efecto, hay materias o aspectos en los que es posible alcanzar acuerdos y, al mismo tiempo, hay que admitir soluciones distintas, plurales en otros temas. La clonación terapéutica es uno de ellos, ya que solo está regulada en algunos países.

Desde esta perspectiva, se puede constatar que la legislación española sobre investigación con embriones mantiene la posición defendida en varios países de la Unión Europea, en torno a cuestiones debatidas como la donación de embriones o la clonación terapéutica y reproductiva. Solo hay que comparar lo establecido por la Carta de Derechos, del año 2000, sobre protección en temas biomédicos, los argumentos defendidos en el Informe CDBI de 2003 sobre protección de embriones, el Informe SEC sobre el uso de células troncales, así como la Resolución del Parlamento Europeo, del año 2005, en materia de investigación. Por tanto la regulación nacional parece coherente con enfoque general - pero no unánime ${ }^{24}$ - que se está dando a los temas biomédicos en países de Europa. Por último, demuestra que el modelo gradualista implica prohibir ciertas técnicas y, al mismo tiempo, aceptar otras que tengan una finalidad terapéutica ${ }^{25}$, incluida la clonación. 


\section{SOCIEDADES PLURALISTAS}

... la Ley se construye sobre los principios de la integridad de las personas y la protección de la digitad e identidad del ser humano en cualquier investigación biomédica que implique intervenciones sobre seres humanos ${ }^{26}$.

El marco normativo que, en algunos países, regula la investigación con embriones - por ejemplo, las leyes españolas de 2006 y de 2007- pretende proteger a los sujetos y garantizar la transparencia de los procedimientos. Parece, además, el modo más adecuado para definir cuál es el uso legítimo de determinadas posibilidades técnicas y, además, fomentar el desarrollo de buenas prácticas en el campo de la investigación. Esto es, prácticas que sean eficaces, transparentes $y$, ante todo, de las que se pueda dar cuenta ante los ciudadanos (López de la Vieja, 2005). Por el momento, en Europa y en otros contextos culturales, sigue habiendo diferencias significativas en torno a la investigación con preembriones y cómo regularla de la manera más adecuada. Sin embargo, una mayor información sobre los aspectos técnicos, jurídicos, sociales y morales del tema ha permitido que los argumentos vayan más allá de la aceptación simple o de la crítica ideológica, atendiendo a las razones de quienes valoran la situación de otra forma. La consideración de la vida humana o el significado que se atribuya a cada una de sus etapas es la clave para llegar a acuerdos más o menos duraderos sobre la protección que merece la vida humana (Hoester, 2002). Ahora bien ¿y si no hubiera acuerdos? Es posible, algo habitual en sociedades pluralistas.

Hay que admitir, entonces, que existen aún profundas discrepancias morales, religiosas e ideológicas a propósito de estos temas. No hay, es probable que no haya una base común (King, 1997) para llegar a acuerdos duraderos. Pero el pluralismo significa que un modelo no puede excluir a otros. En tal sentido, hay que subrayar que las versiones gradualistas, que acepan el empleo de preembriones, reconocen que es necesario protegerlos de forma suficiente ${ }^{27}$. No obligan, sin embargo, a investigar con preembriones, si las propias convicciones lo impidieran. En cambio el no gradualismo y la protección absoluta, llevados a la legislación, dejarían poco espacio para otro tipo de convicciones y, ante todo, para otro tipo de investigación. En suma, el pluralismo - moral, político, ideológico- es un rasgo característico de las sociedades actuales, siendo un primer paso para forjar determinados acuerdos, por mínimos y provisionales que estos sean. Pero quizás suficientes para regular este tipo de investigación, ofreciendo opciones y garantías que, sin la correspondiente legislación, no existirían en este campo. Tener en cuenta los modelos básicos, las tipologías, ayuda, sin duda, a separar los elementos ideológicos de los argumentos sobre derechos y sobre usos legítimos de las técnicas.

Las tipologías son siempre generales, aun así ayudan a entender ciertas diferencias. La versión gradualista reconoce la dignidad de la vida humana potencial y, por tanto, su valor intrínseco. Al mismo tiempo, establece diferencias relevantes entre la vida real y la vida potencial, de modo que los estadios de desarrollo - preembrión, embrión, feto, etc. - son significativos a la hora de determinar el tipo de garantías o de protección a establecer. Una protección no absoluta. En cambio, el enfoque no gradualista concluye que la protección de los embriones y preembriones ha de ser absoluta, habida cuenta de que la vida humana posee dignidad, valor intrínseco, en todas sus fases y, por tanto, merece siempre respeto. Las variantes religiosas de este modelo refuerzan la idea de que la dignidad o santidad de la vida obliga a la protección sin restricciones. En este contexto, "vida humana" y "persona" pueden funcionar como sinónimos, quedando todavía más claro que no ha lugar a practicas que supongan daño o riesgo para los seres humanos ${ }^{28}$, en cualquier etapa. Por consiguiente, los embriones merecen toda la protección y no deberían autorizarse procedimientos que afecten a su integridad o a su vida.

Sobre estas bases, el acuerdo ${ }^{29}$ puede ser difícil, aunque no imposible - si se acepta el pluralismo ${ }^{30}$ como un hecho y como un desiderátum-, una vez se haya asumido que la investigación debe tener una finalidad terapéutica. Esto es, no se permitirá la clonación con fines reproductivos, las técnicas genéticas han de ser usadas en determinadas condiciones y siempre que se cumplan ciertos requisitos $y$, en fin, siempre y cuando, se respete la decisión de los agentes afectados, sin cuyo consentimiento no se aplicarán las técnicas. La primera condición es, por tanto, que los agentes y las instituciones tomen en serio el pluralismo, aunque las doctrinas "omnicomprensivas" -como explicaba J. Rawls (Rawls, 1993, XIII-XXIV)no favorezcan este tipo de acuerdos, provisionales o por "superposición". Solo que las doctrinas de este tipo han de compartir espacios y tiempos con las que no tienen la pretensión, de ser omnicomprensivas. En tal sentido, los valores liberales de la autonomía y la tolerancia resultan más constructivos - no superiores ni inferiores- que los valores absolutos, seculares ${ }^{31} \mathrm{o}$ 
no seculares. La investigación con embriones es uno de los temas que mejor ejemplifica las dificultades que tienen los enfoques no pluralistas y no gradualistas para crear acuerdos (Kass, 2004), al dejar poco margen para quienes adoptan diferentes visiones de la vida y de lo real, pluralistas y gradualistas.

En temas biomédicos, el Convenio de Oviedo indica cómo abrir vías para algunos acuerdos provisionales, razonables. Este documento del año 1997 tiene como objetivo fundamental la protección de los derechos y la dignidad humana, en lo que se refiere a la aplicación de los nuevos avances en medicina y en biología. Por un lado, el Convenio prohíbe la creación de seres humanos con el único propósito de investigar ${ }^{32}$. Por otro, este mismo documento acepta la posibilidad de que la investigación con embriones sea regulada en los países que así lo decidan ${ }^{33}$, a condición de que aseguren una protección adecuada de los derechos (Council of Europe, 1997). Visto en conjunto, el Convenio sigue una línea de argumentación que puede parecer ambigua ${ }^{34}$, al soslayar los inconvenientes de las doctrinas fuertes. Así pues, cabe pensar que las diferencias, por justificadas e importantes que sean, no tienen por qué cerrar espacios para acuerdos sobre temas que suscitan menos controversia, como son el consentimiento de los donantes, la donación con fines reproductivos $^{35}$ e incluso la autorización para los proyectos y los equipos responsables de la investigación con preembriones in vitro, procedentes de las técnicas de reproducción asistida.
En definitiva, esta modalidad de investigación con preembriones suele ser valorada de manera muy diferente, pues algunos autores y algunas instituciones entienden que la vida humana potencial y real merece siempre consideración. Pero la consideración y la protección han de ser proporcionales a su desarrollo. En cambio, otros autores e instituciones entienden que los seres humanos tienen valor intrínseco y, por tanto, merecen respeto, respeto y protección absolutos. Nada ni nadie ha de impedir la expresión de opiniones encontradas sobre esta cuestión, tanto si son favorables como si son desfavorables al uso de determinadas técnicas, no cabe duda al respecto. Sin embargo, las opiniones y creencias personales no tienen por qué traducirse, sin más, en legislación ni en políticas públicas que se decanten por una visión de lo real, una única visión; los individuos tampoco son, sin más, ciudadanos con derechos ni la esfera privada coincide, sin más, con la esfera pública, dos ámbitos relacionados pero bien diferentes ${ }^{36}$. Es decir, leyes y políticas públicas han de garantizar que todas las visiones del mundo tendrán cabida, en su correspondiente esfera y sin eliminar alternativas. La distancia entre regular y prohibir es, pues, considerable, en este como en otros temas controvertidos. Por último, hay que recordar también que la diversidad de puntos de vista, valores y creencias no tiene por qué ser, por principio, una invitación a la controversia y a tensiones sin fin, sino un rasgo valioso de la cultura, la lengua, las creencias de los europeos, tal y como reconocía el Tratado de Ámsterdam en el año 1997.

\section{NOTAS}

1 Ley 14/2006, art.15, c. Por su parte, la Ley 42/ 1998, II, ya se refería al "preembrión" o "embrión preimplantatorio", células resultantes de la división el óvulo, catorce días desde la fecundación. "Feto" corresponde a una fase mas avanzada del desarrollo embriológico.

2 Ley 14/2006, art.11.

3 Ley 14/2006, art.6, art.3, art. 11.

4 Ley 14/2006, art.3, art.5.

5 Ley 14/2006, art.17-19.

6 Ley 14/2006, art.12.
7 Ley 42/ 1998, II.

8 Ley 42/ 1998, art.3.

9 Ley 42/ 1998, art.5,3.

10 C. Romeo Casabona preparó la voz "Embrion" en el volumen 10 palabras clave en nueva genética (Romeo, 2006). Por su parte, P. Femenia se ocupaba de la voz "Embrión", en la Enciclopedia de bioderecho y bioética (Femenia, 2011).

11 Loi no 2004-800, du 6 août 2004.

12 Gesetz zur Sicherstellung des Embyonenschutzes in Zusammenhang mit Einfuhr und Verwendung menschlicher embryonaler Stammzellen (StZG vom 28.06.2002), art. 5, 6 .

13 El Informe señalaba que la investigación con embriones no contaba todavía con una regulación federal, tampoco existía control sobre comercio ni límites claros para prácticas de tipo degradante, mucho menos un sistema uniforme para deliberar y revisar las tecnologías de la reproducción (President's Council on Bioethics, 2004).

14 Siendo todavía cardenal, J. Ratzinger se hizo eco de los criterios defendidos por magisterio de la Iglesia sobre la persona y los temas biomédicos (Congregaziones per la Dottrina della Fede, 1987). 
15 V. Bellver (2002) propone una protección integral.

16 Ley 14/2007, art. 54

17 El Real Decreto 2132/2004, en el art. 1 , ya regulaba el uso de preembriones crioconservados para la investigación en los centros autorizados, preembriones sobrantes o "supernumerarios", procedentes de técnicas de reproducción asistida.

18 La Ley 42/ 1998 planteaba el tema de desarrollo embrionario, desde la fecundación al momento del nacimiento (II).

19 En especial el informe del Comité Asesor en la Investigación Científica y Tecnológica (2003).

20 Ley $14 / 2006$, art. 11.6

21 Ley 14/2006, art. 5.6

22 Ley $14 / 2007$, art. 33.2

23 Loi 2004-800, art.21.

24 Sobre la falta de consenso jurídico en los países de la Unión, (Romeo, 2002).
25 Sobre la finalidad terapéutica y el deber de impedir el sufrimiento, (Guenin, 2001)

26 Ley 14/2007, Preámbulo II.

27 Esto implica reconocer el significado moral de los preembriones y la necesidad de tratarlos con respeto, a pesar de que no sean aún seres humanos plenamente desarrollados, tal como precisaban Foster, Gazzaniga, Rowley y Sandel (2004).

28 T. Shannon (1997) señalaba que, a pesar de que el valor del embrión este asociado al valor de la persona, aquél no suele ser definido con precisión.

29 L. Cahill (1997) se ha referido a la polarización política que incide sobre estos temas, señalando además que los compromisos en torno a ellos no permiten llegar a razonamientos definitivos, si bien ayudan a definir prácticas sociales que resulten aceptables para la mayoría.

30 El argumento a favor de un debate plural se encuentra en (Casado, Egozcue, 2000).
31 C. Strong (1997) se ha referido a la definición de "persona" en un marco secular y a los rasgos asociados a un estatus moral pleno, como son la autoconciencia, la capacidad de pensar y de actuar.

32 Convention on human rights and biomedicine, Oviedo, 1997, art. 18.2.

33 N. Lenoir (2000) ha insistido en el tema del pluralismo en Europa, en relación a este tema.

34 Las ambigüedades lingüísticas del documento han sido señaladas por K. Schmidt, F. Jotterand y C. Foppa (2004).

35 Tema contemplado ya en el año 2000 por los National Institutes of Health, $\mathrm{NIH}$ (2000).

36 L.Guenin (2008) se ha referido a las bases para el consenso y a la esfera pública, en relación al tema, la investigación con embriones.

\section{BIBLIOGRAFÍA}

Barilan, M. (2006). "The Debate on Human Cloning. Some Contributions from the Jewish Tradition". En Roetz, H., CrossCultural issues in Bioethics. The Example of Human Cloning. Amstedam: Rodopi, pp. 311-340.

Bellver, V. (2002). "Las respuestas del Derecho ante las nuevas manipulaciones embrionarias". Cuadernos de bioética, 13 , pp. $47-49$.

Bellver, V. (2001). "Medicina regenerativa y respeto al embrión". Persona y Bioética, 4-5, pp. 41-51.

Cahill, L. (1997). "The Status of the Embryo and Policy Discourse". The Journal of Medicine and Philosophy, 22, pp. 407-414.

Casado, M.; Egozcue, J. (coords.) (2000). Documento sobre investigación con embriones. Barcelona: Observatori de Bioètica i Dret.
Childress, J. F. (1999). Testimony before the Subcommittee on Labour, Health and Human Services and Education of the Committee on Appropriations. Unites States Senate, November 4.

De Miguel, I. (2004). El embrión y la biotecnología: un análisis ético-jurídico. Granada: Comares.

Eich, T. (2006). "The Debate about Human CloniNg among Mulsim Religious Scholars Since 1997". En Roetz, H. (2006) Cross-Cultural issues in Bioethics. The Example of Human Cloning. Amsterdam: Rodopi, pp. 291-309.

Femenia, P. (1999). Status jurídico del embrión humano, con especial consideración al concebido in vitro. Madrid: McGraw Hill.

Glover, J. (1999). "The Sanctity of Life". En Kuhse, H.; Singer, P., Bioethics. Oxford: Blackwell, pp. 193-202.
Gazzaniga, M.; Rowley, J. y Sandel, M. (2004). "Personal Statement". En The President's Council on Bioethics, Reproduction and Responsibility, March, pp. 233-235.

Guenin, L. (2001). "Morals and Primordials". Science, 292, 5522, 1659-1660.

Guenin, L. (2008). The Morality of Embryo Use. Cambridge: Cambridge University Press.

Hoester, N. (2002). Ethik des Embryonenschutzes. Stuttgart: Reclam.

Ioannes Paulus PP.II (1995). Evangelium vitae, 03, 25.

Kass, L. (2004). "Letter of Transmittal”. The President's Council on Bioethics, Reproduction and Responsibility, March.

Kieckbush, D. (2002). "Das Wesen in der Petrischale ernst nehmen". Deutsches Ärztblatt, 46, 3306.

King, P. (1997). "Embryo Research: The Challenge for Public Policy". The Jour- 
nal of Medicine and Philosophy, 22, pp. 423-439.

Klinkhammer, G. (2000). "Ethisches Dilemma der Fortpflanzungsmedizin". Deutsches Äerzteblatt, 47, November, pp. 48-49.

Lacadena, J. R. (2001). "Sentencia del Tribunal de Justicia de la Unión Europea sobre las patentes de células troncales embrionarias humanas. A propósito de un informe jurídico sobre patentes: el concepto y dignidad del embrión humano". Revista de Derecho y Genoma Humano, 35, pp. 145-180.

Lauritzen, P. (2003). "The Ethics of Stem Cell Research". The President's Council on Bioethics, July, 2003, 1-25.

Lenoir, N. (2000). "Europe Confronts the Embryonic Stem Cell Research Challenge". Science, 287, pp. 1425-1427.

López de la Vieja, M. T. (2005). “La Bioética y los ciudadanos". En López de la Vieja, M.T. (ed.), Bioética. Entre la Medicina y la Ética. Salamanca: Publicaciones Universidad de Salamanca, pp. 41-60.

López de la Vieja, M. T. (2008). Bioética y ciudadanía. Madrid: Biblioteca Nueva.

Rawls, J. (1993). Political Liberalism. New York: Columbia University Press.

Roetz, H. (2006). Cross-Cultural issues in Bioethics. The Example of Human Cloning. Amsterdam: Rodopi.
Romeo Casabona, C.; Urruela, A. (2004). “Presupuestos y propuestas para una futura armonización legal en Europa sobre la investigación con células embrionarias humanas". Monografías humanitas, $\mathrm{n} \cong 4$, pp. 215-231.

Romeo Casabona, C. (2006). “Embrión”. En 10 palabras clave en nueva genética. Estella: Ed. Verbo Divino, pp. 110-155.

Romeo Casabona, C. (2002). "Embryonic Stem Cell Research and Therapy: the Need for a Common European Legal Framework". Bioethics, 16, 557-567.

Romeo Casabona, C. (1995). "Consideraciones jurídicas sobre las técnicas genéticas". Anuario de Filosofía del Derecho, XII, pp. 15-38.

Romeo Casabona, C. (2009). “La Ley de Investigacion Biomedica: un nuevo y completo mapa para la investigacion cientifica en medicina". Medicina clinica, 132, pp. 633-637.

Romeo Casabona, C. (2011). Enciclopedia de bioderecho y bioética. Granada: Comares.

Sandel, M. (2005). "Appendix. Personal Statements", The President's Council on Bioethics, Alternative Sources of Human Pluripotent Stem Cells, A White Paper.

Schlink, B. (2002). Aktuelle Fragen des pränatalesn Lebensschutzes. Berlin: De Gruyter.
Schmidt, K.; Jotterand, F.; Foppa, C. (2004). "Neither Convention nor ConstitutionWhat the Debate on Stem Cell Research Tells Us About the Status of the Common European Ethics". Journal of Medicine and Philosophy: A Forum for Bioethics and Philosophy of Medicine, 29, pp. 499-508.

Shannon, T. (1997). "Fetal Status. Sources and Implications". The Journal of Medicine and Philosophy, 22, pp. 415-422.

Singer, P. (1999). "New Assisted Reproductive Technology". En Kuhse, H.; Singer, P., Bioethics, pp. 99-102.

Strong, C. (1997). "The Moral Status of Preembryos, Embryos, Fetuses, and Infants". The Journal of Medicine and Philosophy, 22, pp. 457-478.

Tarodo, S.; Pardo, P. (2011). Biotecnología y Bioderecho. León: Eolas Ediciones.

Tauer, C. (1997). "Embryo Research and Public Policy: A Philosopher's Appraisal". The Journal of Medicine and Philosophy, 22, pp. 423-439.

Tighe, M. (1999). “A Pandora's Box of Social and Moral Problem". En Kuhse, H.; Singer, P., Bioethics. Oxford: Blackwell, pp. 91-95.

Warnock, M. (2002). "Experimentation on Human Embryos and Fetuses". En Kuhse, H.; Singer, P., A Companion to Bioethics. Oxford: Blackwell, pp. 390-396.

\section{PROTOCOLOS, RECOMENDACIONES E INFORMES DE ORGANISMOS OFICIALES}

British Parliament (1990). Human Fertilisation and Embryology Act.

Canadian Institutes of Health Research-ClHR (2005). Ethical Conduct for Research Involving Humans.

Chartre des droits fondamentaux de I' Union européenne (2000), C 364, $18 / 12 / 2000$.

Comisión Interamericana de Derechos Humanos, Organización de los Estados Americanos (2004). Informe № 25/04, Petición 12.361, 11 marzo.

Comité Asesor de Ética en la Investigación Científica y Tecnológica (2003). Informe: La investigación sobre células troncales, Madrid, 24 febrero.

Comité Asesor en la Investigación Científica y Tecnológica (2003). La investigación sobre células troncales, 24 febrero.
Comité Consultatif National d'EthiqueCCNE (1994). Avis sur l' évolution des pratiques d'assistance médicale à la procréation, Rapport no 42-30.

Commission Européenne, GEE (1998). Les aspects éthiques de la recherche impliquant l'utilisation d'embryons humains, 11 septembre.

Commission Européenne, GEE (2000). Opinion No.15 of the European Group on Ethics regarding ethical aspects of human stem cell research and use, November.

Commission of the European Communities (2003). Report on Human Embryonic Stem Cell Research, SEC, 441.

Committee of Experts on Progress in the Biomedical Sciences-CAHBI (1989). Report on Human Artificial Procreation.
Committee on Human Fertilisation and Embryology (1984). Report of the Committee of Enquiry into Human Fertilisation and Embryology, Chairman M. Warnock, July.

Congregazione per la Dottrina della Fede (1987). II Rispetto della vita umana nascente e la dignità della procreacione, 22 febbraio.

Council for International Organizations of Medical Sciences-CIOMS (2002). International Ethical Guidelines for Biomedical Research Involving Human Subjects.

Council of Europe (1997). Convention on human rights and biomedicine, Oviedo.

Council of Europe (2005) Additional Proto$\mathrm{col}$ to the Convention on human rights and biomedicine, concerning biomedi- 
cal research, Council of Europe Treaty Series No.195, 25.I.

Council of Europe (2006), Recommendation Rec. 4 of the Committee of Ministers to member states on research on biological material of human origin.

Department of Health \& Social Security (1984). Report of the Committee of Enquiry into Human Fertilisation and Embryology, July.

Department of Health (2000). Stem Cell Research: Medical Progress with Responsibility. A Report from the Chief Medical Officer's Experts Group Reviewing the Potential of Developments in Stem Cell Research and Cell Nuclear Replacement to Benefit Human Health, June.

Enquete-Kommission (2003). Gutachtliche Stellungnahme Ethik und Recht der modernen Medizin, vom 3.11

Gesetz zum Schutz vom Embryonen (EschG) (1990). Vom 13. Dezember.

Gesetz zur Sicherstellung des Embyonenschutzes in Zusammenhang mit Einfuhr und Verwendung menschlicher embryonaler Stammzellen (2002). (StZG vom 28.06.2002).

Government of Canada (2005), Interagency Advisory Panel on Research Ethics. Section 9: Research Involving Human Gametes, Embryos or Foetuses.

House of Commons, Committee (2005). Report Science and Technology-Fith Report, 14 March.
Ley 14/2006, de 26 de mayo sobre técnicas de reproducción human asistida, $\mathrm{BOE}$ no 126, 27 mayo 2006.

Ley 14/2007, de 3 de julio, de Investigación biomédica, BOE nN 159, 4 julio 2007.

Ley 35 /1998, 22 noviembre 1988, sobre técnicas de reproducción asistida, BOE n 280 .

Ley 42/1988, 28 diciembre 1988.

Ley 45/2003, 21 noviembre 2003, por la que se modifica la Ley 35/1988, sobre Técnicas de Reproducción Asistida, BOE n 280.

LOI no 2004-800, 6 août 2004 relative à la bioéthique, Journal Officiel, 7 août 2004.

National Institutes of Heatlh-NIH (2000). Guidelines for Research Using Human Pluripotent Stem Cells and Notification of Request for Emergency Clearance, August 25.

Pontificia Accademia per la vita (2000). Intervento dell'Archivescovo J.L.Tauran, VII Assemblea Generales, febbraio.

Pontificia Accademia per la vita (2003). Comunicato finale. Etica della Ricercha biomedica. Per una visiones cristiana, IX Assemblea Generales, 24-26 febbraio.

President's Council on Bioethics (2001). Bush, G.W.: Remarks by President on Stem Cell Research, Appendix B, August 9.

President's Council on Bioethics (2002). Human Cloning and Human Dignity. An Ethical Inquiry.
President's Council on Bioethics (2004). Reproduction and Responsibility: The Regulation of the New Biotechnologies.

President's Council on Bioethics (2004). Reproduction and Responsibility, March 2004.

President's Council on Bioethics (2005). Alternative Sources of Human Pluripotent Stem Cells, A White Paper, May.

Real Decreto 2132/2004, de 29 de octubre.

Steering Committee on Bioethics-CDBI (1998). Medically assisted procreation and the protection of the human embryo: CDBI/INF (98) 8.

Steering Committee on Bioethics-CDBI (2003). The Protection of the Human Embryo in vitro and Fetus, Report CDBICO-GT3, 13.

Tribunal Constitucional de Costa Rica (2000). Sentencia prohibiendo la fecundación in vitro, Sala Constitucional, Corte Suprema de Justicia, San José, 15 de marzo 2000, ExP 95-001734-0007-CO

Zentralen Ethikkommission (2001). SteIlungnahme zur Stammzellforschung, November.

Zentralen Ethikkommission (2006). SteIlungnahme sur Wahrung ethischer Grundsätze in der Medizin und ihre Grenzengebieten zum Forschungskl en mit Ziele therapeutischer Anwendung, 1. Februar. 